\title{
Problems of forming and developing person's aesthetic ideal
}

\author{
Aktamkul Rafikovich Samadov ${ }^{1}$ \\ ${ }^{1}$ Associate professor, Chair of national ideology and citizen's society \\ Candidate of philosophical sciences, Samarqand state university, Uzbekistan \\ Email:samadov a@umail.uz
}

\begin{abstract}
This article is about analysis of problems of forming and developing person's aesthetic ideal, structure of aesthetic consciousness, and levels. Aesthetic ideal includes aesthetic consciousness and aesthetic activity, features connected with aesthetic attitude to reality are analysed.

Keywords: ideal, aesthetics ideal, aesthetics consciousness, person, art, sport, aesthetics, feeling, taste, moral ideal, adolescence, education-upbringing, spirituality, aesthetics culture.

\section{INTRODUCTION}

It is well known that such areas of knowledge as psychology, pedagogy, jurisprudence, philosophy and sociology are known to be part of the problem of personality. Creation, structure, elements, and the analysis of the individual as a whole and as an integral part of society, differing opinions about the individual.

Erickson developed the concept of psychological development of the person, which was divided into eight periods. The philosopher and psychologist of the 20th century, E. Fromm, concludes that the inborn and acquired qualities of a person are inseparable, characterize the individual and represent him in a unique way. In general, the theme of personality is well-researched in the social and humanitarian areas, emphasizing the individual identity, indivisibility and the ideal formation of the person, emphasizing that they fulfill various functions in society. Thus, the question of the comprehensive formation of the personality, the formation of the perfect person and the theoretical model of its aesthetic ideal, the role of the aesthetic ideal in the person's aesthetic consciousness are relevant.
\end{abstract}

\section{MAIN PART}

In philosophical movements it can be seen that personality problems were more active in the 19th and 20th centuries than in the early days. At this time the ideas of personalism, which studied the individual as a unique social phenomenon, the ideas of pragmatism as the owner of active and useful works, the ideas of Freudism. The factors of personality education and creation were studied by ancient scholars of the East and by religious and philosophical currents, which included theoretical, theological ideas of human factors and capacities. In the West, the problem of personality began to be explored at a time when social and economic growth and human creativity increased.

Psychoanalysts have profound insight into the creation, structure, ideals, influences, and the inner and outer "I" as a result of extensive philosophical, psychological and sociological studies. Now, as a research object, the human personality has become the object of study in all social and humanitarian sciences. Only Z. Freud's psychoanalyst states that the study of all layers of personality is a product of complex processes such as the acquisition of id, ego, and superego in which the processes of conscience, self-reflection and ideals $[1,10]$. Therefore, personality is a complex social phenomenon.

The creation of a unique phenomenon of the human personality makes it necessary to create the theoretical ideal of the person. Numerous studies have been done in this regard to analyze the ideal, social, and practical, and make it the belief of the person to be created. These researchers were tasked with categorizing the ideal, not going beyond the ideological framework, and developing what they 
needed only for those who were ideologically prepared. The orders of this period were fulfilled and a number of scientific works were published.

The importance of the formation of human aesthetic consciousness is the subjective form of aesthetic relations, first and foremost, of making deep, complex and meaningful representations, evaluations, and judgments about objects that are directly related to aesthetic value and objects. Aesthetic consciousness is manifested in spiritual need, generates a certain attitude to reality, and is then represented by the specific actions that form the basis of the activity, its element. Although the need for a certain aesthetic relationship is nevertheless not considered as aesthetic.

Aesthetic need is a component of the general need and always reflects people's need for certain aspects of their spiritual life, including important activities and spiritual values that enable them to receive certain spiritual nourishment from the community in which they live and maintain that spiritual wealth. Hence, the aesthetic needs of people are reflected in the objective demands of human activity. "Man understands everything by observing the laws of the soul... Therefore, there is an aesthetic source in any human activity: in the course of its activities, a person lives with the spirituality of joy - joy, hope, freedom - and seeks a social appraisal as measured by the subtle criteria of self and others.

The aesthetic understanding and the beginning of the process of action are based on the aesthetic need. The aesthetic need is of both natural and biological and socio-spiritual significance as the basis of all aesthetic events that occur in human life; the "beautiful" elegance, the appetite for refinement, while maintaining the aesthetic appeal of the person, will be further refined throughout his lifetime, and will serve the aesthetic discussion, aesthetic evaluation, aesthetic taste and aesthetic ideal. The level of culture and spiritual capacity of each person is measured by the range of his or her aesthetic needs.

As a result of evolution, human aesthetic consciousness went through different stages. Human thinking has transcended various boundaries and boundaries, modernizing its feelings and needs, and manifesting itself through art.

"Person has expressed his needs through art and has developed the sensual state of mind through the art of movement and thinking".

The world of aesthetic events encompasses all areas of human aesthetics, labor, housing, and human value. Aesthetic values are realized not only through art in the minds of people, but also through a sport that takes a modern-cultural look and captures the needs and interests of people. The process of aesthetizing events, activities, areas of life, and art in the society can now be carried out only in accordance with the requirements of postmodern culture.

This process shows that the boundaries of the aesthetic scale have been expanded, and the object of human aesthetic needs has changed. It is the sport that defines the object of the aesthetic activity and creates a common aesthetic space, rapidly entering our socio-cultural life. Nowadays, a large number of people are using sports to create physical culture and healthy living.

The most saturated element of the emotional part of aesthetic consciousness is the aesthetic taste in the formation of aesthetic relationships. It is emotionally influenced by aesthetic consciousness and is understood as "the ability of the individual to perceive and evaluate aesthetic values at the level of cognitive activity and consciousness. Aesthetic taste is a system of aesthetic preferences and appraisals of an individual". Thus, a number of individual factors are interdependent and interrelated, leading to the formation of aesthetic activities. Aesthetic consciousness feels the need for interaction.

A systematic analysis of aesthetic consciousness and aesthetic attitudes shows that the constituent elements of the aesthetic are disorganized in relation to one another. Aesthetic emotion, aesthetic experience characterizes the emotional area of the individual; aesthetic feelings and aesthetic perceptions are personal qualities, and their formation is characterized by aesthetic evaluation, aesthetic taste, and aesthetic observation - the interrelation of the intellectual and emotional spheres of the human being. The aesthetic ideal combines the rational and emotional spheres of the individual.

Another aspect of this analysis is that all the components of aesthetic consciousness reflect the harmony (and its features) of the object and, therefore, in the perception of an object, attention must be paid to the individual attributes of its image - emotional, emotional, and intellectual. In this connection we can say that the parallel development of all elements of aesthetic consciousness, with little or no emotional harmony, is manifested in the process and practice of cognition. 
There are understanders of emotional and emotional harmony as sensory-intellectual abilities or perceptual-evaluative abilities, and symmetry and asymmetry as measurement units.

Harmony is a conceptually significant capability that evolves over the course of human life, the main theme of its time, the spiritual and spiritual world of the individual. The aesthetic ideal, as noted in the "Big Psychological Dictionary," is that the "psychic action" that is supposed, imagined, anticipated, anticipated, planned, thoughtful, is reflected in the perceived emotional, figurative, evaluative-logical representations, "rising" from the realm of unconsciousness, partly becomes the content of consciousness.

Many pedagogical, psychologic and philosophical studies of personality aesthetic consciousness (S.L. Rubinstein, B.T. Likhachev, E. Kvyatkowski, E.L. Yakovleva, S.T. Pogorelov, G.I. Ratgauz, L. P. Pechko) prefer to seek out external factors of the formation of aesthetic consciousness in research. Similarly, research identifies external factors that influence the development of all the constituent elements of aesthetic consciousness. One of these factors is the aesthetic activity of the individual and his / her types. That is, from aesthetic perception to independent creative activity.

By examining the stages of the formation of aesthetic consciousness in the formation of personality, one can draw the following conclusions: Firstly, the period of formation of aesthetic consciousness and its elements in the child, adolescence and adolescents under the influence of sociopsychological factors coincides with the aesthetic ideal; secondly, the formation of aesthetic consciousness of the individual is divided into stages, levels, and depends on the age and features of the social environment; Third, aesthetic consciousness has a system of values that are manageable and difficult to control, including the period of artistic and creative subconscious processes, the growth of self-awareness of one's own power; fourthly, the formation of a personalized layer can, in turn, be followed by aesthetic ideal, such as aesthetic ideal, idol, standard, model, model; fifthly, the formation of a person's attitude to aesthetic value and aesthetic reality (positive and negative) implies a controversial, irreconcilable struggle for the social problems posed by the aesthetic culture of society, the discussion of objects and subjects. Because the creative, the individual passes the social environment through the prism of its advanced aesthetic ideal and sets the boundaries between beauty and ugliness.

The third form of manifestation of aesthetic ideal in art is a contradictory image. This controversial, controversial modus appears in early art. The critical, satirical portrayal of reality gives the person the ability to discover beauty, to distinguish ugly and beauty from various vices. The artist creates his hero, the athlete, in an ideal, perfect way, separating his performances from that contradictory, conflicting reality. For example, the good manners of Alisher Navoi are caused by the presence of imperfect, immoral people around him.

According to A. Erkaev, who studied the aesthetic consciousness and the manifestation of the aesthetic ideal in it, “... the hero does not achieve his goal for various reasons and is a victim. The heroine's demise causes the viewer and the reader to be frightened and helps to clear away the small things - envy, greed, and greed. The hero of the tragedy represents the high ideals of society. The higher ideals are beautiful in their essence, they nurture humanity, kindness, justice and thirst for truth. Thus, tragedy is the emergence of beauty itself. And, on the contrary, comedy helps to get rid of the feelings and passions of life."

The result of this contradictory, antinomical thinking (antithetism) is the manifestation of the aesthetic ideal. The aesthetic ideal of the person is the constructive value of the ideal, which organizes the internal and external conditions of human activity in art and sport, from natural to artificial reality.

A positive hero is always modus of aesthetic consciousness of the person, artificially growing from the natural-aesthetic being, and using the antithetical way to create an ideal image of historical figures and athletes in the artistic field. "Heroic action is a unique, creative movement. The artist, who is writing the work, works day and night, desiring his aesthetic ideal. So, heroic action is not just courage, but selfless, persistent, heartbreaking quest."

It represents the aesthetic ideal in art through the laws of beauty (symmetry, antithetism, altitude, power, etc.). We call it aesthetic ideal. The aspiration to represent the aesthetic ideal in art and sport is expressed in the aesthetic consciousness of the person by the following legal process:

* The existence of an internal indication of the subject's search for some form of aesthetic ideal; 
* Indirect expression of aesthetic ideal in the nature of evaluation of "imperfect" artistic images;

* Reflection of the aesthetic ideal in artistic and artistic reconstruction of art and its rejection;

* Positive characters of the aesthetic ideal - the direct expression of the ideal carriers in the images;

* Certain aspects of the aesthetic ideal, the actual carriers of the personal porter's lines the formation of the present "old" ideal of the future and the "young tree" ideal;

* Focusing on the artistic and image model of the future, the aesthetic condition of the artistic-abstract.

According to the above analyzes, the formation of the aesthetic ideal is a complete change in the aesthetic consciousness of the individual, from the linear thinking to the nonlinear vision, the transboundary formation of the new order from the old order of the elements of aesthetic consciousness. Practical action of a person to create aesthetic ideal creates the elements of aesthetic consciousness, creation of versatile, perfect creativity, a number of features of the aesthetic consciousness system: plays a key role in the organization of the interaction; secondly, by making choices of moral and aesthetic values, they create their own institutional and functional forms appropriate to their space and time; thirdly, aesthetic knowledge helps to transform from emotional-perspectives to beliefs (epistymology); fourthly, the aesthetic creates creativity in the aesthetic consciousness due to its organizational properties and develops aesthetic sense, aesthetic look, aesthetic taste of the person; Fifth, the aesthetic develops creative abilities in the ideal person and influences their practical activities.

The aesthetic ideal begins to be perceived in the form of love, enjoyment, the pursuit of life and the pursuit of it, the intellectual and physical maturity of the individual, the beauty of the objective existence. Aesthetic understanding and perception of the universe, theory and practice are modeled in the formation and development of the person's aesthetic consciousness.

It is important to note that this period has advanced beyond the other theoretical considerations of the ideal, with its focus on seeking the ideal of life itself.

But the first reason for the "realization" of such an ideal was primarily because of the "separation" of morality from church doctrines, and the second reason was that morality was understood as a manifestation of the "natural law" of humanity. The natural character of human morals and ideals has become the natural self-preservation of human beings, their survival, reproduction and enjoyment, and their affection for themselves and others. Respect and respect for the individuality of the individual eventually led the thinkers of the eighteenth and eighteenth centuries to the level of humanization of the human mind, the search for ideals, goals and dreams from the activities of the pure mind.

Philosophers such as Descartes, Spinoza, Russo, Walter, Lametri, Geleltsi, Golbach, and Didro all envision the promising human ideals of beauty and oppose the vital, living and natural ideal of medieval religious doctrine.

A number of complex problems have emerged in the thinking of mankind: why is it difficult for the Creator to achieve or fulfill his own ideals of people who are equal in terms of nation and society? Why do members of a nation united for one purpose long for different ideals because of their own needs and capacities?

So ideally apart from the universal meaning, individual, personal, national, and social factors are so intertwined that this process changes some aspects of the ideal concept based on the demands of time. "Creating something new is one of the most noble qualities of a person. Only a person's ability to keep quiet, to stay calm, and to strive for perfection is inherent to him. Therefore, man is aware of his own imperfections, in fact culture and civilization originate from this perception".

The views of the person's aesthetic mind and its ideal conception are differently analyzed in the teachings of the German classical philosopher I. Kant. I. Kant linked the "ideal issue" with the moral and spiritual perfection of man: he considered the ideal as "a goal and a desire to achieve it". The philosopher also emphasizes that the moral-aesthetic ideal should be sought from the mind rather than the reality. It is not the ideals and phenomena that emerge from the empirical reality, but from the logical integrity of various images, concepts and emotions that have the potential for thinking. 
In ideal literature and art, he expresses his "absolute" and "lasting" state in the form of artistic images. In this area, common (normative attributes) and individuality (character traits) are represented by the ideal images of the intersection of integrity and fragmentation, morality and freedom, essence and reason, necessity and chance. Therefore, the beauty expressed in art is considered ideal. In this sense, From I. Kant's aesthetic ideal, the following conclusions can be drawn:

first, the ideas and ideals of aesthetic ideal are intended to serve as proof of the doctrine of "on its own", based on Kant's a priori theory; secondly, beauty and grandeur, expediency, the transcendental nature of man, independent of his theoretical mind, is a priori ability connected with his heart and beliefs and ideas of eternity; third, if the idea (beauty, grandeur) expresses the essence of empirical events in reality, ideally it is an expression of logical integrity that unites these ideas; fourthly, the ideals and ideals of human life are determined not by moral criteria and imaginations, but mainly by the laws of thought and mental activity; fifthly, in Kant's doctrine, the aesthetic ideal is explained by the notions of beauty or grandeur, and argues that "beauty and eventuality, which combine in terms of harmony, order, harmony, and perfection". This doctrine argues that the theoretical methodological aesthetic ideal is a complex conscious activity. Therefore, Kant describes the ideal born as an a priori product of thought when he connects the ideas born with empirical phenomena with emotional perception. Because the idea is tested in practice, it calls for the creation and consolidation of new ideas of ideal thinking.

\section{CONCLUSION}

Aesthetic consciousness is two complementary aspects of human consciousness, which are recognized as part of social consciousness and are intertwined with each other, with each other influenced by each other. Aesthetic consciousness consists of a complex system, such as human creativity, subtlety, intelligence, infinite senses, perception, taste and aesthetic ideal. There is no great difference between a person and aesthetic ideal. The universal, national characteristics have a great influence on the mind of the person, but the aesthetic consciousness is formed as a whole and its maturity forms the aesthetic ideal.

The concept of aesthetic ideal arises as a result of the aesthetic consciousness and aesthetic activity of the individual, and includes the great task of understanding the world through the aesthetic attitude of the person to reality and the laws of beauty. With this function it rules the inner world and rules the outside world. In essence, the aesthetic ideal in terms of functionality is usually to set a person's purpose, to indicate the direction of his activity, to determine the future horizon. The ideal analogy of natural things is a form of human activity in which a person creates an image, an image, and justifies his immortality.

Thus, aesthetic consciousness creates the natural, value-based nature of things through the aesthetic ideal and affects the minds of people in a variety of ways and means. In this section of our research, we conclude:

First, the study of the role of aesthetic ideal in aesthetic consciousness is a special theme in the history of philosophy. The purpose of living in the aesthetic ideal person's mind included the period of formation of vital imperatives, creating polarization of aesthetic reality;

secondly, the formation of aesthetic consciousness is a complex that depends on the age, social features, educational, cognitive, spiritual and ideological state of the person, which is involved in everyday life (taste, perception, aesthetic activity), scientific-creative (aesthetic reality, culture, aesthetics perception) in the aesthetic ideal);

thirdly, classical ideas about the aesthetic mind and the aesthetic ideal belong to I. Kant and V. Hegel, who explain the aesthetic ideal through the concepts of beauty or grandeur, and that it is the beauty of something and phenomenon that is based on harmony, order, harmony, and perfection. Those who believed that the apparent image of an ideal purpose was an empirical reality, an expression of an absolute idea;

fourth, if the ideal of high morality and aesthetics in the mind of the person is not ideal, he becomes a simple performer and participant of the reality, a vague, indifferent person who is not aspiring to the future, unable to ascertain his spirituality, or to become indifferent. remains.

The creative person, along with the expansion of his aesthetic consciousness, forms his aesthetic ideal and leaves the world a unique work of art, a way of creation; 
fifth, the aesthetic is one of the elements that are formed within the ideal aesthetic consciousness but have a larger weight. He has a creative attitude towards the individual, demonstrates the effectiveness of his creativity, and is constructive in his or her choice of innovation in personal activities.

\section{REFERENCES}

1. Choriev A. Human Philosophy. An independent person. Chinor ENK, Tashkent 2002, p.10

2. Husanov B. Elegance philosophy. (methodical manual) - Tashkent: NUUz. 2009, page 16

3. Gerasimova I.A. Philosophical conscious of dance// Issues of philosophy. - 1998.- No. 4, p-50

4. Yakovleva E.L. Emotional mechanisms and details. - 1997. - No. 4, - p. 23.

5. Kulaeva G. M. Aesthetic ideal in the system formatting values of pupils who study in the Russian language. Abstract of diss.doct. of ped.sciences, M.: 2008, p-32. 